\title{
Development of an ethogram/guide for identifying feline emotions: a new approach to feline interactions and welfare assessment in practice
}

\author{
Sandra Louise Nicholson ${ }^{*}$ (I) and Roslyn Áine O'Carroll
}

\begin{abstract}
Background: An accurate assessment of feline behaviour is essential in reducing the risk of handler injury and evaluating/improving feline welfare within veterinary practices. However, inexperience and/or suboptimal education in feline behaviour may cause many veterinary professionals to be ill equipped for this. In addition, busy veterinary professionals may not have time to thoroughly search the literature to remediate this deficiency. Upon searching the literature, terms such as aggression and stress predominate, but these do not completely represent the rich mental lives that cats are now understood to have. Emotions have recently emerged as an alternative approach to animal behaviour/welfare assessment. However, few resources describe how to identify them, and positive emotions are particularly neglected. In addition, no simple, broad, and concise guide to feline emotions currently exists within the research literature. Therefore, this research aimed to develop a straightforward and clear reference guide to feline emotions (ethogram) to aid veterinary professionals in interpreting feline behaviour in practice and for use in veterinary education.

Results: Five primary emotions were identified and defined for domestic species (fear, anger/rage, joy/play, contentment and interest). A feline emotions guide (feline emotions ethogram) was created. Three hundred and seventy-two images were captured of feline behaviours indicative of emotional states. Of these, ten of the best quality and most representative images were selected to illustrate the guide (two of each emotional state). The feline emotions guide and its associated images were subsequently validated by two feline behaviour experts.

Conclusions: Following slight modifications, the emotions definitions yielded during the feline ethogram design process may be transferable to other domestic species. The feline emotions ethogram/guide itself may be particularly helpful for distinguishing immediate motivations and customising patient care within short- term veterinary contexts. Hence, its use may improve feline welfare and feline handling/interactions. However, the guide will need to be reliability tested/ tested in the field and may require adaptation as the feline emotions' knowledge base grows. In addition, novices may benefit from exposure to more images of feline emotional state, particularly those involving mixed emotions. Freely available online images and videos may be sourced and used to supplement the accompanying image bank.
\end{abstract}

Keywords: Feline emotions, Feline behaviour, Feline welfare assessment, Risk (feline handling), Animal behaviour education

\footnotetext{
*Correspondence: sandra.nicholson@ucd.ie

School of Veterinary Medicine, University College Dublin, Dublin, Ireland
}

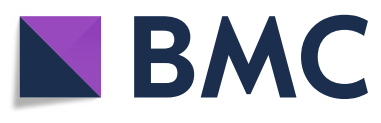

(c) The Author(s). 2021 Open Access This article is licensed under a Creative Commons Attribution 4.0 International License, which permits use, sharing, adaptation, distribution and reproduction in any medium or format, as long as you give appropriate credit to the original author(s) and the source, provide a link to the Creative Commons licence, and indicate if changes were made. The images or other third party material in this article are included in the article's Creative Commons licence, unless indicated otherwise in a credit line to the material. If material is not included in the article's Creative Commons licence and your intended use is not permitted by statutory regulation or exceeds the permitted use, you will need to obtain permission directly from the copyright holder. To view a copy of this licence, visit http://creativecommons.org/licenses/by/4.0/ The Creative Commons Public Domain Dedication waiver (http://creativecommons.org/publicdomain/zero/1.0/) applies to the data made available in this article, unless otherwise stated in a credit line to the data. 


\section{Background}

Veterinary professionals in small animal or mixed practice regularly assess feline behaviour in order to safely interact with cats and monitor their wellbeing. Errors in assessment may lead to personal injury and/or negative animal welfare consequences. Cat-attack injuries are very common in veterinary nurses $[1,2]$ and veterinarians $[1$, $3]$, and they may lead to physical damage, emotional distress [1, 4], work absences [1] and secondary infections [3]. Research has suggested that recently qualified veterinary professionals have the greatest risk of injury. Nordgren et al. [4] found that veterinary nurses with fewer than 5 years' experience in practice and those younger than 25 years of age were more likely to incur bite wounds than their older, more experienced colleagues. Similarly, Epp and Waldner [3] noted that veterinarians with full-time experience of 5 years or less were more likely to report bite injuries. This may reflect the fact that animal behaviour education $[5,6]$ and feline handling experience [7] can be limited during undergraduate training. Limited experience with cats may also affect the ability of the veterinary professional to assess feline wellbeing. This is problematic as cats often find aspects of the veterinary environment very challenging $[8,9]$. These aspects may include restrictive housing, altered daily routines, noise, and exposure to unfamiliar smells or individuals $[8,9]$. The distress experienced could prevent cats from engaging in maintenance behaviours such as eating, drinking, sleeping, and elimination [8]. In addition, distress may alter clinical parameters [8]. The net result is that patient care and animal welfare are compromised. To avoid this, veterinary professionals (particularly trainees or recent graduates) need guidelines on how to assess feline behaviour. Typically, animal welfare assessment involves the use of behavioural and hormonal (cortisol) indicators of stress [10]. However, the stress response is not a specific indicator of poor welfare, as it may be stimulated by positive or negative circumstances [11]. Therefore, new indicators are needed for assessing feline welfare and evaluating the risks of handling/interaction. Emotions may be the key. Studies in neuroscience have provided evidence for the existence of emotions in animals $[12,13]$. As emotions influence behaviour [14], an understanding of the cat's emotional state may help veterinary professionals to predict the risk of handling and plan interactions. They can also provide insight into how the animal perceives its environment [14] and thus are useful tools for assessing animal welfare. However, the literature on feline emotions, although growing, is still limited, and most resources focus on negative (unpleasant) emotions or emotional valence. It is important that positive (pleasant) emotions are not neglected, as their consideration can bring a balanced perspective to safety and welfare assessments. The presence of positive emotions may signal good welfare $[15,16]$ and suggest that the cat will cooperate with staff. Busy veterinary professionals may not have time to comprehensively review the literature on feline emotions and so may value a tool that summarises and interprets it. In consideration of all this, our project aimed to create a balanced, illustrated, and entry level reference guide to feline emotions (feline emotions guide/ethogram) for use by veterinary professionals and in veterinary education.

\section{Materials and methods}

\section{Identifying and defining feline emotions}

In order to create a feline emotions guide/ethogram, it was first necessary to determine which emotions were valid and recognisable in animals and to clearly define these. A literature search was conducted for this purpose. Scholarly textbooks were accessed for foundational material and academic search engines (University College Dublin (UCD) One Search, Wiley Online Library, Google Scholar, JSTOR, PubMed, Science Direct and Ingenta Connect) were used to find relevant journal articles. The existence of secondary emotions in animals (such as jealousy, pride and empathy) was supported by anecdotal evidence only [17]. Therefore, these were not explored further. However, the existence of primary emotions in animals was strongly supported by neuroscientific studies, as detailed by Panksepp [12, 13]. Therefore, Panksepp's "emotional circuits" (seeking, fear, anger/rage, lust, care, panic, and play) $[12,13]$ were used as the basis for the emotions. Anxiety was not distinguished from fear $[12,13]$ and a further search of the literature revealed no specific neuronal circuitry to support its inclusion. In addition, frustration was not listed as a core emotion [12, 13]. Instead, it was determined to be a state leading to anger/rage rather than a distinct emotion [12]. Therefore, it was not selected as a core emotion for the guide. For our purposes, only emotions directly observable in a clinical setting would be useful. As many feline patients are neutered and/or are housed singly, lust $[12,13]$ was excluded from the emotions guide. Care $[12,13]$ was excluded because it would only be seen when nursing queens and their kittens are hospitalised together, and this is not a very common occurrence. Finally, panic $[12,13]$ was excluded because it was thought to be too difficult to distinguish from extreme fear. The remaining systems (seeking, fear, anger/ rage and play) $[12,13]$ were judged to be appropriate for inclusion. Seeking and play $[12,13]$ were considered to reflect actions rather than emotions and so new identifiers were sought to replace these terms. As seeking indicates a desire to explore and interact with the environment and obtain resources [13], "Interest" was judged to be an appropriate term. An emotion was also 
required to represent the pleasure associated with the satisfaction of this desire. This was not included in Panksepp's emotional circuits [12, 13]. However, interconnected "pleasure centres" have been identified in the brain, and stimulation of these centres causes a "liking" response [18]. This inspired the choice of "Contentment" as a primary emotion. Play was renamed "Joy" as per Panksepp's $[12,13]$ description of that system. Once selected, the primary/core animal emotions were defined with reference to the literature (see Table 1). Both animal behaviour/veterinary behaviour and human psychology literature (particularly resources on positive psychology) were drawn upon to create these definitions. Each definition included the type of emotion (whether it is a positive or negative sensation). This is customary in psychology and also significant for animal welfare. The general triggers/causes for each emotion were included in the definitions, as this is helpful for assessing and modifying the environment. Each definition was completed by the addition of the behavioural strategies/types used to express emotion. Behavioural strategies are more commonly referred to in the literature than animal emotions. Therefore, this approach was necessary in order to make the connection between emotional states and their specific behaviours. The definitions were originally created in 2016. However, they were further refined and improved in 2019-2020. In particular, "Joy" was renamed "Joy/Play" in response to feedback received from an anonymous reviewer. The reviewer had commented that feline object play may involve a predatory drive rather than simply joy. The definition of "Joy/Play" was also expanded to include the behavioural strategies involved in play (play categories), as described in the literature $[25,26]$.

\section{Design of the feline emotions guide/ethogram}

The definitions created for each core feline emotion acted as a foundation for designing the behaviour guide. The behavioural strategies were used to find individual behaviours and/or postures/body language associated with each emotion. For example, aggressive or threatening behaviours (towards any target but not associated with predation) were sought as indicators of anger/rage and play behaviours were sought as indicators of joy. During an additional literature search, a behaviour directory (ethogram) for wild and domestic cats was discovered [32]. This directory detailed numerous feline behaviours/postures and also grouped them into broad categories [32]. Some of these categories were similar to the behavioural strategies used in our definitions (affiliative, calm, aggressive and agonistic, exploratory) [32]. Fear was presented as a specific category and play was listed under "active behaviours." [32] Therefore, this ethogram, created by Stanton et al. [32], was a rich source of information for the design of the feline emotions guide. However, details were also obtained from other sources such as Bradshaw et al. [33], Finka et al. [34], Overall [35], and Shaw \& Martin [36]. Vocalisations were omitted, as a single type of vocalisation may be used to express more than one type of emotion [35] and there may be individual differences in vocalisations between cats [37]. The first version of the ethogram was completed in 2016. However, it was later updated (in 2019 and 2020) to include items from more recent academic papers [38-40]. It was also reorganised for clarity and conciseness. To make the guide easy to use, it was divided into sections comprised of body language/postures (eyes, ears, tail, body), actions, risk of handler injury, and risk of welfare issue. Anger/rage and fear were categorised as a high risk to welfare because they are unpleasant emotional states that animals seek to avoid [12, 13]. In addition, they may be aroused by a suboptimal environment involving challenges (anger/rage) [23] or perceived danger (fear) [20]. Interest and joy/play were categorised as moderate risks to welfare. In neuroscientific studies, animals actively seek to stimulate the "Interest" system indicating that this is likely to be associated with pleasant sensations [23] and hence positive welfare. In addition, play is often associated with positive welfare states [26]. However, the unsatisfied motivation to explore or play could result in frustration and ultimately anger/rage. In this case, negative welfare would also

Table 1 Definitions of feline primary emotions

\begin{tabular}{|c|c|}
\hline Emotion & Definition \\
\hline Fear & $\begin{array}{l}\text { Negative emotional state [19] caused by immediate perceived danger or the threat of danger [20] and manifested as vigilance and } \\
\text { attempts to withdraw or escape [21]. }\end{array}$ \\
\hline Anger/Rage & $\begin{array}{l}\text { Negative emotional state [22] caused by the frustrated desire to perform actions/achieve goals [12] (including escape or exploration) or } \\
\text { by competition for resources [23]. Manifested as aggression or the threat of aggression [22]. }\end{array}$ \\
\hline Joy/Play & $\begin{array}{l}\text { A high intensity positive emotional state [24], which may be internally motivated [23]. Manifested as non-functional behaviours involv- } \\
\text { ing physical activity (locomotor play), interaction with other individuals (social play), or interaction with objects (object play) [25, 26]. }\end{array}$ \\
\hline Contentment & $\begin{array}{l}\text { A positive emotional state caused by the fulfilment of the animal's needs and desires and an acceptance of their current state [27]. } \\
\text { Manifested as resting [28], calm [29], and affiliative behaviour [29]. }\end{array}$ \\
\hline Interest & $\begin{array}{l}\text { A positive emotional state [28], caused by the presence of a novel stimulus or stimulus of salience and/or anticipation of engagement } \\
\text { [30]. Manifested as attention and orientation to the stimulus }[30,31] \text { and/or seeking behaviours }[12,13] \text {. }\end{array}$ \\
\hline
\end{tabular}


result from the unmet expectancies or needs. Contentment was categorised as a low risk to welfare, as by definition it is based on having all needs met [27]. As anger/rage may result in aggression [22], this emotion was categorised as a high risk to the handler. In addition, as frustrated fear, interest or joy/play may lead to anger/ rage, they were categorised as moderate risks to the handler. However, contented cats do not perceive an immediate threat to their wellbeing. Therefore, contentment was categorised as a low risk to the handler.

\section{Image capturing, editing and selection}

To support and illustrate the emotions guide, multiple photographs were taken of cats displaying behavioural indicators of each emotional state. These were obtained from within the rescue cattery of "Drogheda Animal Rescue" (DAR) and collected in summer 2016. The study received approval and exemption from a full ethical review by the University College Dublin (UCD) Animal Research Ethics Committee (AREC-E-16-10-Nicholson). For ethical reasons, ill cats were not involved, and negative emotional states were only captured if naturally expressed. However, positive emotional states were encouraged through play, petting, and interaction (when appropriate). A Canon EOS 1000D, Panasonic HDCSD60, Canon PowerShot SD1200 IS, and a Samsung Galaxy S5 were used interchangeably throughout the three-week shooting period. Good natural lighting created optimal conditions for acquiring images. Flash use or low light levels may have artificially affected pupil size and confounded the interpretation of emotion. Where possible, cage bars were not included in the images to allow for a clear view of the subject. Every effort was made to exclude contextual information such as toys, food etc. from images. It was thought that these could distract from the body language of the pictured cat and/ or provide independent "clues" to the cat's emotional state. Once collected, the images were categorised based on the emotion depicted, and edited (as needed) to reduce blurring and improve contrast. Ten of the best quality and most representative images were selected to illustrate the emotions guide (two images for each emotional state). Images representing a single emotion were preferred to those involving mixed emotions, as it was thought that these would be easiest for a novice to interpret/learn.

\section{Validation}

In autumn/winter 2020, the feline emotions guide/ethogram and associated images were sent to two different individuals for (content) validity testing. These individuals were both certified clinical animal behaviourists (CCABs) from the United Kingdom. A number of changes were made to the feline emotions guide/ ethogram as a result of their feedback. "Slapping feet against ground" and the tail position of "Upright and bent over the body" (which were previously listed under anger/rage and taken from Stanton et al. [32]) were removed, as they were deemed inappropriate by the validators. In addition, behaviours involved in friendly greeting or hunting/predation were explicitly categorised as such. A caveat was added that pupil size/shape could be affected by arousal or light levels in addition to emotional state. Finally, one validator also advised that the researchers study their outputs carefully to ensure that they were satisfied with the final product. As a result of this, the researchers added items from more recent literature [38-40] to the feline emotions ethogram.

\section{Results}

Feline emotions guide/ethogram

Please see the completed feline emotions guide/ethogram (Table 2) below.

\section{Images obtained}

In total 372 images were obtained, and 109 of these were worthy of further consideration. Amongst the 109 selected images, interest (26\%), contentment (21\%), and fear $(15 \%)$ were captured most frequently. Anger/rage $(2 \%)$ and joy $(1 \%)$ were captured least frequently. Mixed emotions (i.e. involving more than one emotion) were also regularly observed (35\%) (see Fig. 1). Ten of the best quality and most representative images were selected to illustrate the emotions guide (two images for each emotional state) Fig. 2.

\section{Discussion}

\section{Considerations for the use of the research outputs}

This research yielded definitions of emotions, and an accessible "entry level" resource for veterinary professionals to use in identifying feline emotions. The definitions and approach used could also be transferable to other domestic species. However, "Lust" and "Care" $[12,13]$ may first need to be added for species where reproduction is more important (horses or farm animals, for example). Use of the feline emotions guide/ethogram may improve feline interactions, reduce the risk of handler injury, and enhance the welfare of feline patients. It may also be particularly useful for teaching undergraduate students and supporting recently qualified individuals (who are more vulnerable to injury [3, 4]). It amalgamates a multitude of information that is normally scattered throughout the literature and includes details on positive emotions that can often be difficult to find. Unlike other resources, it is designed to be used "live" at the time of interaction to guide feline handling and to respond to any changes in the patient's wellbeing during procedures. In this way, it can aid the individualisation 
Table 2 Feline emotions ethogram/guide [32-36, 38-40]

\begin{tabular}{|c|c|c|c|c|c|c|c|}
\hline \multirow[t]{2}{*}{ EMOTION } & \multicolumn{4}{|l|}{ BODY LANGUAGE } & \multirow[t]{2}{*}{ ACTIONS } & \multirow{2}{*}{$\begin{array}{l}\text { RISK OF } \\
\text { HANDLER } \\
\text { INJURY }\end{array}$} & \multirow{2}{*}{$\begin{array}{l}\text { RISK OF } \\
\text { WELFARE } \\
\text { ISSUE }\end{array}$} \\
\hline & EYES & EARS & TAIL & BODY & & & \\
\hline Fear & $\begin{array}{l}\text { Wide open eyes } \\
{[35,39] \text { with }} \\
\text { round dilated } \\
\text { pupils [35]. } \\
\text { Blinking or half } \\
\text { blinking [38]. } \\
\text { Or eyes tightly } \\
\text { shut [39] or } \\
\text { avoidance of eye } \\
\text { contact [33, 36, } \\
\text { 39]. } \\
\text { Gaze to left in } \\
\text { mild fear states } \\
\text { [38]. }\end{array}$ & $\begin{array}{l}\text { Flattened }[34] \text { to } \\
\text { the side }[33,35, \\
\text { 36] or back [32, } \\
\text { 35, 36, 38]. } \\
\text { Ear pinnae are } \\
\text { not visible [35]. }\end{array}$ & $\begin{array}{l}\text { Tucked under the } \\
\text { body or wrapped } \\
\text { around it }[32,36 \text {, } \\
39] \text {. }\end{array}$ & $\begin{array}{l}\text { Piloerectio } \\
\text { n[36, 39]. } \\
\text { Tense } \\
\text { muscles [39]. } \\
\text { Crouching } \\
\text { [32, 38, 39]. } \\
\text { Lowered } \\
\text { head [36, 39] } \\
\text { Standing } \\
\text { with arched } \\
\text { back [35]. } \\
\text { Left head } \\
\text { turn in mild } \\
\text { fear [38]. }\end{array}$ & $\begin{array}{l}\text { Vigilance [39]. } \\
\text { Startle [39]. } \\
\text { Trembling [32, 39]. } \\
\text { Freezing [32, 38, 39]. } \\
\text { Hiding [32, 38, 39]. } \\
\text { Fleeing/avoidance [32, 38, 39]. } \\
\text { Grooming [32]. } \\
\text { No maintenance behaviours } \\
\text { (eating, drinking, elimination)/ } \\
\text { sleep [39]. }\end{array}$ & MODERATE & $\mathrm{HIGH}$ \\
\hline Anger/Rage & $\begin{array}{l}\text { Pupils oblong } \\
\text { and dilated [35]. } \\
\text { Direct stare [32, } \\
\text { 35, 36]. }\end{array}$ & $\begin{array}{l}\text { Swivelled } \\
\text { sideways [33- } \\
\text { 35]. Inner pinnae } \\
\text { are visible [35]. }\end{array}$ & $\begin{array}{l}\text { Lowered and rigid } \\
\text { [35]. Held in } \\
\text { inverted L shape } \\
\text { [36]. } \\
\text { Slapping against } \\
\text { ground [32]. } \\
\text { Rapidly moved } \\
\text { from side to side } \\
\text { (or up and down) } \\
\text { [32] (Tail lash [33]). }\end{array}$ & $\begin{array}{l}\text { Piloerection } \\
\text { [32, 36] along } \\
\text { spine and tail } \\
\text { [36]. } \\
\text { Leaning } \\
\text { forward [36]. } \\
\text { Elevated } \\
\text { rump [36]. } \\
\text { Standing } \\
\text { with arched } \\
\text { back [35]. }\end{array}$ & $\begin{array}{l}\text { Exposing teeth [32]. } \\
\text { Launching at/chasing individual } \\
\text { [32]. } \\
\text { Attacking with paws or mouth } \\
\text { [32]. } \\
\text { Displace others [32]. }\end{array}$ & $\mathrm{HIGH}$ & $\mathrm{HIGH}$ \\
\hline Joy/Play & $\begin{array}{l}\text { Pupils dilated/ } \\
\text { round due to } \\
\text { arousal [35]. } \\
\text { Or relaxed/soft } \\
\text { [32]. }\end{array}$ & $\begin{array}{l}\text { Upright and } \\
\text { forward facing } \\
\text { [36]. }\end{array}$ & $\begin{array}{l}\text { Vertical [33]. May } \\
\text { take an inverted U } \\
\text { shape [35]. }\end{array}$ & $\begin{array}{l}\text { "Play face" in } \\
\text { kittens: a } \\
\text { half- open } \\
\text { mouth [32, } \\
\text { 40]. } \\
\text { Arching } \\
\text { spine }[32,40] \text {. } \\
\text { Body posture } \\
\text { varies. }\end{array}$ & $\begin{array}{l}\text { Locomotor play [40] } \\
\text { Climbing [40]. Running. } \\
\text { Social play [40] } \\
\text { Approaching cat [40]. } \\
\text { Jumping [40]. } \\
\text { Patting, pawing playmate [40]. } \\
\text { Grabbing playmate with } \\
\text { forelimbs [40]. } \\
\text { Biting playmate [40]. } \\
\text { Rolling/presenting belly [32, 40]. } \\
\text { Wrestling playmate [40]. } \\
\text { Kicking/raking playmate [40]. } \\
\text { Chasing playmate [40]. } \\
\text { Side stepping or running away } \\
\text { from playmate [40]. } \\
\text { Object play [40] } \\
\text { Rearing to reach object [40]. } \\
\text { Pawing [25, 40], batting object } \\
\text { [40]. } \\
\text { Holding object with paws [40]. } \\
\text { Sniffing, licking object [40]. } \\
\text { Biting [25, 40], chewing object } \\
\text { [40]. } \\
\text { Throwing object [40]. } \\
\text { Wrestling with object [40]. } \\
\text { Predatory: Stalking, chasing, } \\
\text { jumping, pouncing on object } \\
\text { [40]. }\end{array}$ & MODERATE & MODERATE \\
\hline Contentment & $\begin{array}{l}\text { Pupils are small } \\
\text { miotic vertical } \\
\text { ovals [35]. } \\
\text { Half open [36]. }\end{array}$ & $\begin{array}{l}\text { Upright and } \\
\text { forward facing } \\
{[32,36] \text {. }}\end{array}$ & $\begin{array}{l}\text { Tail relaxed and } \\
\text { still [36]. } \\
\text { May be erect and } \\
\text { slightly curled [32, } \\
35] \text {. }\end{array}$ & $\begin{array}{l}\text { Sitting [32]. } \\
\text { Lying curled } \\
\text { up in circular } \\
\text { formation } \\
\text { [32]. }\end{array}$ & $\begin{array}{l}\text { Stretching [32]. } \\
\text { Yawning [32]. } \\
\text { Grooming self or other } \\
\text { (allogrooming) [32]. } \\
\text { Kneading/treading paws [32]. } \\
\text { Friendly greeting (nose } \\
\text { touching/sniffing, head butting, } \\
\text { rubbing face and body against } \\
\text { object/individual-allorubbing) } \\
\text { [32]. } \\
\text { Rolling onto back or from side } \\
\text { to side [32]. }\end{array}$ & LOW & LOW \\
\hline
\end{tabular}


Table 2 Feline emotions ethogram/guide [32-36, 38-40] (Continued)

\begin{tabular}{|c|c|c|c|c|c|c|c|}
\hline \multirow[t]{2}{*}{ EMOTION } & \multicolumn{4}{|l|}{ BODY LANGUAGE } & \multirow[t]{2}{*}{ ACTIONS } & \multirow{2}{*}{$\begin{array}{l}\text { RISK OF } \\
\text { HANDLER } \\
\text { INJURY }\end{array}$} & \multirow{2}{*}{$\begin{array}{l}\text { RISK OF } \\
\text { WELFARE } \\
\text { ISSUE }\end{array}$} \\
\hline & EYES & EARS & TAIL & BODY & & & \\
\hline & & & & & $\begin{array}{l}\text { Nuzzling [32]. } \\
\text { Eating [32]. } \\
\text { Clawing object [32]. }\end{array}$ & & \\
\hline Interest & $\begin{array}{l}\text { Dilated/round } \\
\text { pupils [35]. } \\
\text { Gaze to right [38]. } \\
\text { Observing an } \\
\text { individual or } \\
\text { object [32]. }\end{array}$ & $\begin{array}{l}\text { Upright and } \\
\text { directed forward } \\
\text { towards } \\
\text { stimulus }[32,36] \text {. } \\
\text { Ear flick [36]. }\end{array}$ & $\begin{array}{l}\text { Depends on } \\
\text { context. } \\
\text { Horizontal [33]. } \\
\text { Tail up/vertical in } \\
\text { friendly greeting } \\
\text { [33]. }\end{array}$ & $\begin{array}{l}\text { Standing on } \\
\text { hindlimbs } \\
\text { [32]. } \\
\text { Resting } \\
\text { forepaws } \\
\text { against } \\
\text { object [32]. } \\
\text { Stretching } \\
\text { head out } \\
\text { forward [36]. } \\
\text { Head turn to } \\
\text { right [38]. }\end{array}$ & $\begin{array}{l}\text { Exploring the area or objects } \\
\text { [32]. } \\
\text { [32]Sniffing . } \\
\text { Lickin g[32]. } \\
\text { Pawing [32]. } \\
\text { Friendly greeting (touching } \\
\text { noses with another cat or } \\
\text { rubbing face \& body against } \\
\text { object/individual-allorubbing) } \\
\text { [32]. } \\
\text { Hunting (stalking, chasing, } \\
\text { pouncing, grabbing, biting) [32]. }\end{array}$ & MODERATE & MODERATE \\
\hline
\end{tabular}

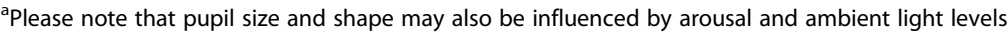

of care and complement pre-emptive measures, such as nursing care plans and the feline friendly handling and environmental guidelines issued by the International Society of Feline Medicine (ISFM) and the American Association of Feline Practitioners (AAFP) [8, 41]. However, it is intended for use in the short term and is not suitable for determining long-term welfare (cognitive bias or quality of life tools could be used for this instead). To aid novices, the feline emotions guide is organised by the body part/body language indicators or "actions" involved in each emotion. However, the indicators and actions should be used holistically. Some occur with more than one emotional state (piloerection or pupil dilation for example), while others may be more specific (for example play indicators for joy, or flattened ears for fear). The feline emotions guide should be used to distinguish emotions and their associated motivation(s) to determine whether corrective action is necessary. Although both anger/rage and fear signal potential animal welfare issues and/or risk to staff, their underlying motivations differ. Anger/rage is often motivated by frustration (e.g. of exploration, interaction, or accessing resources) [42]. Ideally, frustration would be noted and acted upon prior to anger developing. Frustration manifests as restless behaviours such as pacing, biting or leaning against barriers, scratching, excessive rubbing or pawing, and the disruption of cage contents [39]. With signs of either frustration or anger, cats should be given access to appropriate resources (such as food, water, and litter-trays) and the opportunity to engage in their desired behaviour (such as play, exploration, appropriate stroking) if possible. Alternatively, these cats may simply need a break

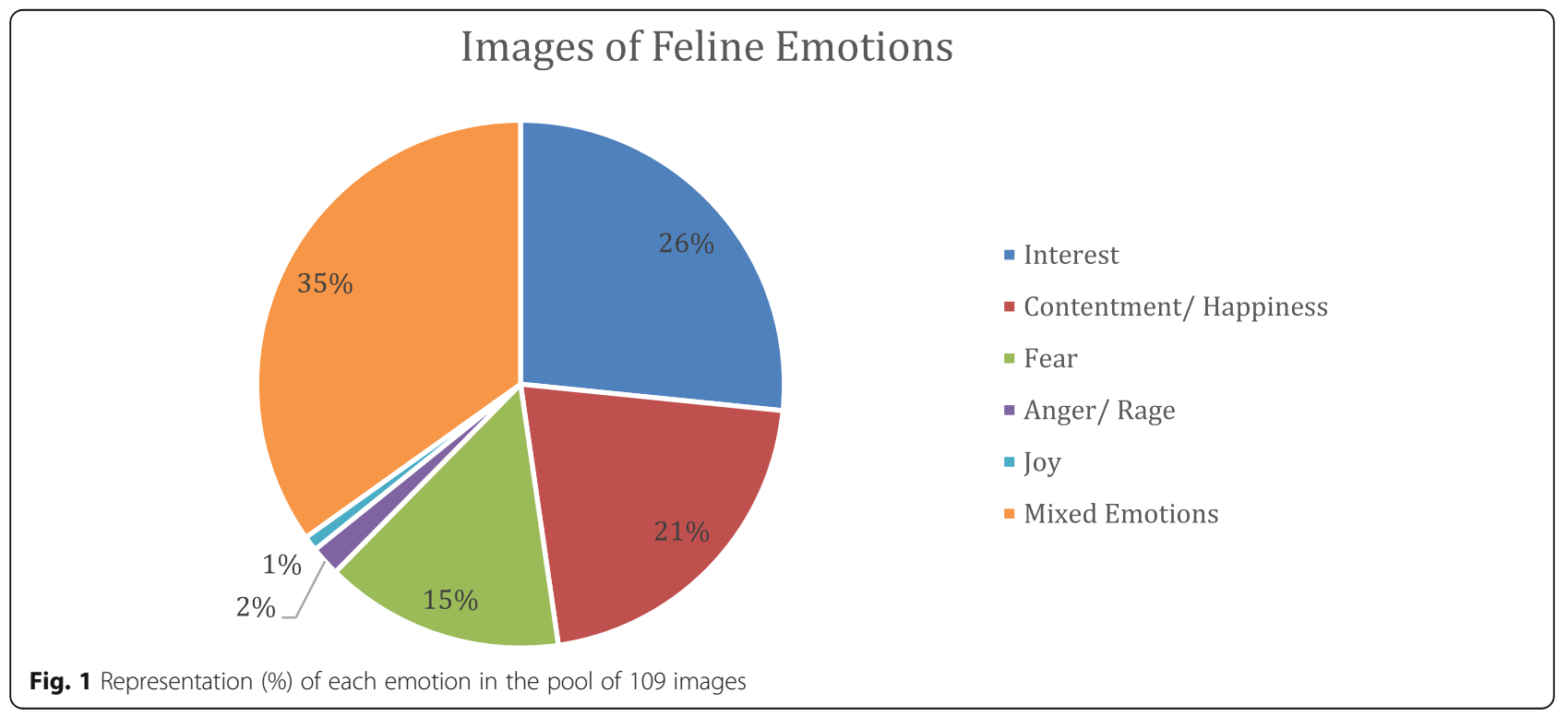




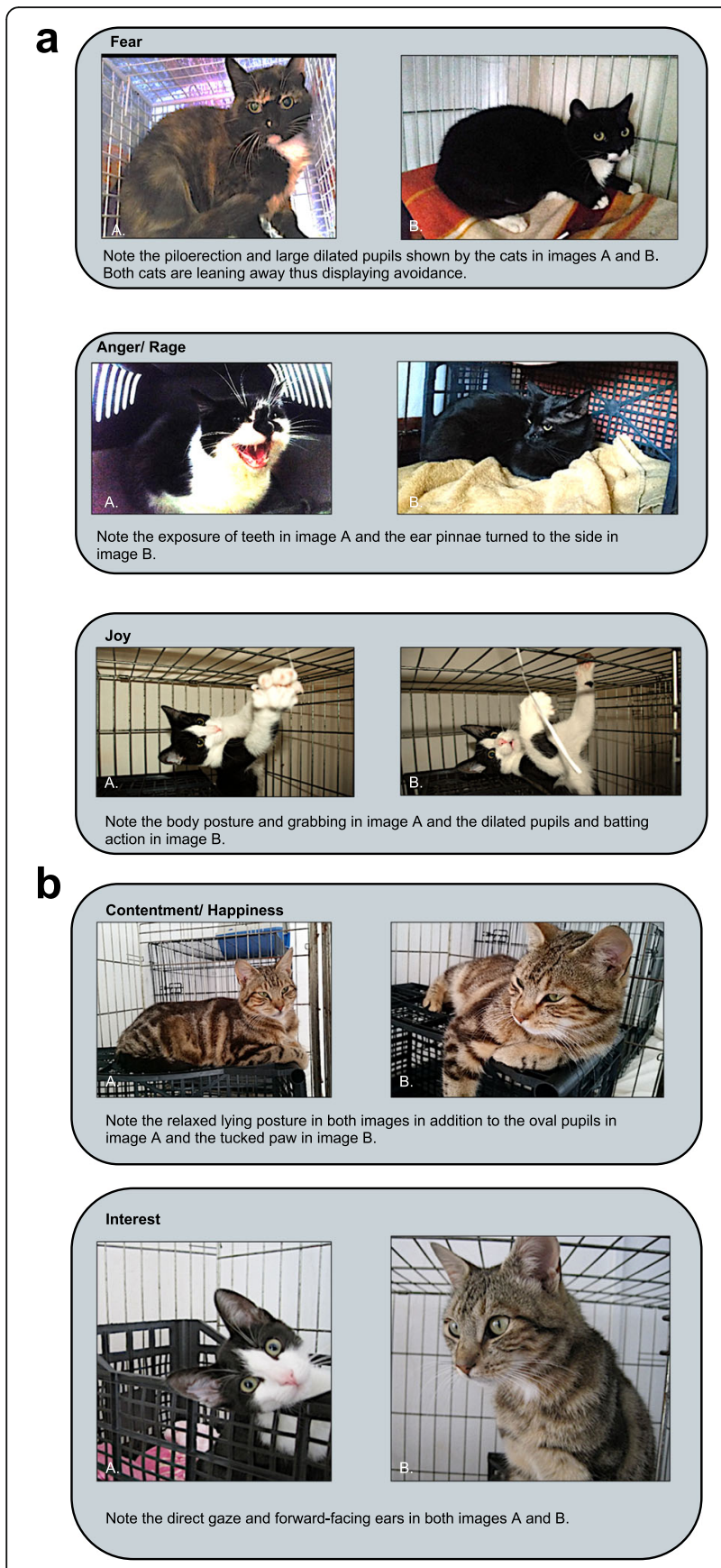

Fig. $\mathbf{2}$ a and $\mathbf{b}$ : Feline Emotions Images

from handling or disturbance. Unlike anger/rage, fear is motivated by the presence of a perceived danger [20]. Therefore, fearful cats should be given the opportunity to withdraw or hide [43]. Cat cages or carriers could be covered with a towel or blanket, or a hide could be added to hospital cages for this purpose [44]. Distinguishing positive emotions also enables veterinary professionals to better cater to their patients' needs. An interested cat may be seeking stimulation/interaction and a joyful cat may wish to continue playing, while a contented cat has all its current desires and needs met. The interested cat could be provided with toys, feeding enrichment, appropriate petting, or visual stimulation to prevent frustration. Appropriate play could be continued with the joyful cat. Contentment may be sustained and further promoted by treating the cat as an individual and liaising with its owner to discover its usual routines and preferences. When evaluating feline emotional state, veterinary professionals should be aware that multiple emotions (mixed emotions) can co-exist in the individual at the same point in time. Indeed, mixed emotions were commonly observed during the project fieldwork. However, mixed emotions may also be more challenging to interpret and require more practice to identify. In all cases, veterinary professionals must remain attentive to the cat's body language to confirm the success or ongoing effectiveness of their interventions.

\section{Future modifications to the feline emotions ethogram/ guide}

The feline emotions guide/ethogram has not yet been reliability tested or trialled in the field and some modifications may be required once these processes have been completed. In addition, much still remains unknown about feline emotions, and as the knowledge base grows it may be necessary to adapt the guide. For example, wider use of the Cat Facial Action Coding System (CatFACS), a programme that codes the movements of facial muscle groups [38], could yield new information on the facial expressions involved in feline emotional states. In addition, research in the underexplored area of play in adult cats [40] could find that its characteristics differ significantly from the characteristics of play in kittens. Additional core emotions may be discovered or confirmed in future and require inclusion in the guide. In particular, anxiety was omitted from the feline emotions guide, but it may be necessary to review this decision in future. It was excluded because no specific neuronal circuitry was found to provide evidence for it being distinct from fear. Indeed, the terms "Anxiety" and "Fear" are often used interchangeably in veterinary behaviour. Panksepp and Watt hypothesised that emotional systems may actually consist of "families" of interrelated and gradated emotions rather than isolated core emotions [23]. If so, anxiety may be part of the fear "family" or a form of fear itself. Indeed, both anxiety and fear are responses to perceived danger, and both arise from activation of the amygdala [20]. Anxiety is considered to involve uncertainty about potential danger, while fear is considered to involve apprehension about immediate danger [20]. However, alternatively, some findings from psychiatric research suggest that anxiety is a valid and distinct animal emotion. Animals (usually rodents) placed into experimental contexts involving uncertainty about danger 
have been found to use behavioural strategies similar to those employed by humans experiencing anxiety [45]. These behavioural strategies included avoidance, escape, vocalisation, hypervigilance, investigation (by sniffing), grooming, and conflicted approach-withdrawal [45]. Interestingly, the performance of some of these behaviours was also reduced following the administration of anxiolytics (benzodiazepines for example) [45]. Although these findings are suggestive, further research is needed to identify anxiety-specific neuronal structures in animals and specific behaviours in cats, prior to anxiety's inclusion in the feline emotions ethogram/guide.

\section{Collecting additional images to support the feline emotions ethogram/guide}

In future, in addition to making necessary adjustments to the feline emotions ethogram, more images will be needed to complement it. Although many images were collected during the original project fieldwork, fewer than 30\% were suitable and of sufficient quality and clarity to be associated with the feline emotions ethogram/guide. Mixed emotions often occurred but these were excluded to simplify the ethogram/guide for beginners. However, these images could be useful for developing further competence in the interpretation of feline emotional signalling. The images selected for use did not illustrate all of the behavioural signs/body language of each feline emotion. In addition, anger/rage and fear were poorly represented, as these emotional states were rarely shown by the cats involved in the study. This may be attributed to the excellent care provided by the shelter staff and/or the considered approach taken by the field researcher. Joy was also displayed infrequently, perhaps because confinement in the shelter cages somewhat impeded play behaviours, or because few young cats/kittens were housed in the shelter at the time. Obtaining images in the field is a rather challenging and time intensive task. However, freely available online images and videos from sources such as Google Images and YouTube respectively could be gathered more efficiently and may also be suitable for use. One of the authors is currently using images from these sources to support the teaching of feline behaviour and her experiences will be reported elsewhere.

\section{Conclusions}

The aim of this project was to create a feline emotions ethogram/guide for use by veterinary professionals and in veterinary education. However, the design process itself also yielded definitions of primary emotions that may be transferable to other species. The completed feline emotions ethogram/guide will aid veterinary professionals in identifying and distinguishing feline emotional states (both positive and negative) in the moment. This may allow motivations to be determined and improvements to be made to both animal welfare and handler health and safety. The ethogram should be used holistically and continuously, and with the understanding that mixed emotions often occur. The feline emotions ethogram will need to be reliability tested and trialled in the field to confirm its usefulness. It may also need to be modified or added to in the future as the research base advances. Finally, additional images should be gathered to enhance its illustration. Images and videos featuring feline behaviour are now freely available online and may reduce the need to capture additional images in the field.

\section{Abbreviations \\ UCD: University College Dublin; DAR: Drogheda Animal Rescue; CCAB: Certified Clinical Animal Behaviourist; ISFM: International Society of Feline Medicine; AAFP: American Association of Feline Practitioners; CatFACS: Cat Facial Action Coding System}

\section{Acknowledgements}

We are very grateful to Drogheda Animal Rescue (DAR) for their participation in this project. Many thanks to Mark Carty and Carla Coll for their assistance with the editing, archiving, and formatting of the feline emotions images. We are very grateful to Julie Bedford BSC (Hons), PGCE, PG. Dip (CABC), CCAB and Trudi Atkinson RVN Dip.(AS) CABC, CCAB for their helpful feedback and validation of the feline emotions ethogram/guide. We also very much appreciate the comments from anonymous reviewers that led to enhancement of our manuscript.

\section{Informed consent}

Informed consent was obtained from the legal custodian of all animal(s) described in this work.

\section{Conflict of interests}

The authors declared no potential conflicts of interest with respect to the research, authorship, and/or publication of this article.

\section{Prior publication}

This research (in an earlier form) was presented as a poster at the University College Dublin (UCD) Undergraduate Research Scholarship and Arts (URSA) symposium on 28th September 2016.

\section{Authors' contributions}

SN-conceptualisation of the study and supervision of the project. SN and ROC- design of the methodology. SN and ROC-investigation of the literature. ROC-project fieldwork. SN and ROC-image selection. ROC-image editing and archiving. SN and ROC-writing of the manuscript. SN-revision of the manuscript. Both authors read and approved the final manuscript.

\section{Funding}

This work was supported by the Interchem Ireland "Summer Student Research Bursary" in 2016. The funding body had no role in the design of the study, analysis/interpretation of information, or writing of the manuscript.

Availability of data and materials

Data sharing is not applicable to this article as no datasets were generated or analysed during the current study.

\section{Declarations}

Ethics approval and consent to participate

This study received an exemption from full ethical review from the University College Dublin (UCD) Animal Research Ethics Committee (AREC-E-16-10Nicholson).

\section{Consent for publication}

For any animals individually identifiable within this publication, informed consent for their use in the publication was obtained from the people involved. 


\section{Competing interests}

The authors of this manuscript declare no competing interests. Also, all authors have agreed to publish this article.

Received: 23 December 2020 Accepted: 16 March 2021

Published online: 25 March 2021

\section{References}

1. Drobatz KJ, Smith G. Evaluation of risk factors for bite wounds inflicted on caregivers by dogs and cats in a veterinary teaching hospital. J Am Vet Med Assoc. 2003:23(3):312-6. https://doi.org/10.2460/javma.2003.223.312.

2. Van Soest EM, Fritschi L. Occupational health risks in veterinary nursing: an exploratory study. Aust Vet J. 2004;82(6):346-50. https://doi.org/10.1111/j.1 751-0813.2004.tb11101.x

3. Epp T, Waldner C. Occupational health hazards in veterinary medicine: Zoonoses and other biological hazards. Can Vet J. 2012;53:144-50. https:// www.ncbi.n/m.nih.gov/pmc/articles/PMC3258827/.

4. Nordgren LD, Gerberich SG, Alexander BH, et al. Evaluation of risk and protective factors for work-related bite injuries to veterinary technician certified in Minnesota. J Am Vet Med Assoc. 2014;245(4):434-40. https://doi. org/10.2460/javma.245.4.434.

5. Shivley CB, Garry FB, Kogan LR, et al. Survey of animal welfare, animal behavior, and animal ethics courses in the curricula of AVMA council on education-accredited veterinary colleges and schools. J Am Vet Med Assoc. 2016;248:1165-70. https://doi.org/10.2460/javma.248.10.1165.

6. Golden O, Hanlon AJ. Towards the development of day one competencies in veterinary behaviour medicine: survey of veterinary professionals' experience in companion animal practice in Ireland. Ir Vet J. 2018;71(12):1-9. https://doi.org/10.1186/s13620-018-0123-3

7. Dunne K, Brereton B, Duggan V, et al. Motivation and prior animal experience of newly enrolled veterinary nursing students at two Irish third-level institutions. J Vet Med Educ. 2018;45:413-22. https://doi.org/10.3138/jvme.1216-186r.

8. Carney HC, Little S, Brownlee-Tomasso D, et al. AAFP and ISFM felinefriendly nursing care guidelines. J Feline Med Surg. 2012;14(5):337-49 https://doi.org/10.1177\%2F1098612X12445002.

9. Hewson C. Evidence-based approached to reducing in-patient stress. Part 1: Why animals' sensory capacities make hospitalization stressful to them. VNJ. 2014;29:130-2. https://doi.org/10.1111/vnj.12130.

10. Dawkins MS. A user's guide to animal welfare science. Trends Ecol Evol. 2006;21(2):77-82. https://doi.org/10.1016/j.tree.2005.10.017.

11. Selye $H$. Forty years of stress research: principal remaining problems and misconceptions. CMAJ. 1976;115:53-6. https://www.ncbi.n/m.nih.gov/pmc/a rticles/PMC1878603/.

12. Panksepp J. Affective neuroscience: the foundations of human and animal emotion. New York: Oxford University Press; 1998. p. 41-58.

13. Panksepp J. Affective consciousness: Core emotional feelings in animals and humans. Conscious Cogn. 2005;14:30-80. https:/doi.org/10.1016/j.concog.2004.10.004.

14. Levine ED. Feline fear and anxiety. Vet Clin North Am Small Anim Pract. 2008;8(5):1065-79. https://doi.org/10.1016/j.cvsm.2008.04.010.

15. Boissy $A$, Manteuffel $G$, Jensen MB, et al. Assessment of positive emotions in animals to improve their welfare. Physiol Behav. 2007;92(3):375-97. https:// doi.org/10.1016/j.physbeh.2007.02.003.

16. Morton DB. A hypothetical strategy for the objective evaluation of animal wellbeing and quality of life using a dog model. Anim Welf. 2007;16(1):75-81 https:/ www.ingentaconnect.com/content/ufaw/aw/2007/00000016/a00102s1/art00011.

17. Morris PH, Doe C, Godsell E. Secondary emotions in non- primate species? Behavioural reports and subjective claims by animal owners. Cognit Emot. 2008;22(1):3-20. https://doi.org/10.1080/02699930701273716.

18. Vytal K, Hamann S. Neuroimaging Support for Discrete Neural Correlates of Basic Emotions: A Voxel-based Meta-analysis. J Cogn Neurosci. 2010;22(12): 2864-85. https://doi.org/10.1162/jocn.2009.21366.

19. Mineka S. Individual differences in the acquisition of fears. In: Hermans $D$, Rimé B, Mesquita B, editors. Changing emotions. East Sussex: Psychology Press; 2013. p. 47. Available from: ProQuest Ebook Central.

20. Steimer, T. (2002). The biology of fear- and anxiety-related- behaviors. Dialogues Clin Neurosci, 4(3), 231-249. https://dx.doi.org/10.31887\%2FDCNS. 2002.4.3\%2Ftsteimer

21. Lerner JS, Keltner D. Beyond valence: Toward a model of emotion-specific influences on judgement and choice. Cognit Emot. 2000;14(4):473-93. https://doi.org/10.1080/026999300402763.
22. Siegel $A$, Shaikh MB. The neural bases of aggression and rage in the cat. Aggress Violent Behav. 1997;2(3):241-71. https://doi.org/10.1016/S1359-1789(96)00010-9.

23. Panksepp J, Watt D. What is Basic about Basic Emotions? Lasting Lessons from Affective Neuroscience. Emot Rev. 2011;3(4):387-96. https://doi.org/1 $0.1177 \% 2 F 1754073911410741$.

24. Nealis LJ, Van Allen ZM, Zelenski JM. Positive Affect and Cognitive Restoration: Investigating the Role of Valence and Arousal. PLoS One. 2016; 11(1):e0147275. https://doi.org/10.1371/journal.pone.0147275.

25. Held SDE, Špinka M. Animal play and animal welfare. Anim Behav. 2011 81(5):891-9. https://doi.org/10.1016/j.anbehav.2011.01.007.

26. Ahloy-Dallaire J, Espinosa J, Mason G. Play and optimal welfare: Does play indicate the presence of positive affective states? Behav Process. 2018;156: 3-15. https://doi.org/10.1016/j.beproc.2017.11.011.

27. Berenbaum $H$, Huang AB, Flores LE. Contentment and tranquillity: Exploring their similarities and differences. J Posit Psychol. 2019;14(2):252-9. https:// doi.org/10.1080/17439760.2018.1484938

28. Fredrickson BL. The broaden-and-build theory of positive emotions. Philos Trans R Soc Lond Ser B Biol Sci. 2004:359(1449):1367-77. https:/doi.org/10.1098/rstb.2004.1512.

29. Gilbert P. An Evolutionary Approach to Emotion in Mental Health With a Focus on Affiliative Emotions. Emot Rev. 2015;7(3):230-7. https://doi.org/1 $0.1177 / 1754073915576552$

30. Silvia PJ. Interest-The curious emotion. Curr Dir Psychol Sci. 2008;17(1):5760. https://doi.org/10.1111\%2Fj.1467-8721.2008.00548.x

31. Spielberger CD, Starr LM. Curiosity and exploratory behavior. In: O'Neil HF, Drillings M, editors. Motivation: theory and research. Oxon: Routledge; 2012.

32. Stanton LA, Sullivan MS, Fazio JM. A standardized ethogram for the felidae: A tool for behavioral researchers. Appl Anim Behav Sci. 2015;173:3-16. https://doi.org/10.1016/j.applanim.2015.04.001.

33. Bradshaw JWS, Casey RA, Brown SL. The behaviour of the domestic cat. 2nd ed. Oxfordshire: Cabi; 2012. p. 98-101. https://doi.org/10.1079/9781845939922.0000

34. Finka L, Ellis SLH, Wilkinson A, et al. The development of an emotional ethogram for Felis silvestris focused on FEAR and RAGE. J Vet Behav. 2014; 9(6):e5. http://dx.doi.org/10.1016\%2Fj.jveb.2014.09.018.

35. Overall K. Manual of clinical behavioral medicine for dogs and cats. St. Louis: Elsevier Health Sciences; 2013. p. 312-59.

36. Shaw JK, Martin D. Canine and feline behavior for veterinary technicians and nurses. 1st ed. Ames: Wiley Blackwell; 2014. p. 54-6.

37. Nicastro N, Owren MJ. Classification of domestic cat (Felis catus) vocalizations by naive and experienced human listeners. J Comp Psychol. 2003;117(1):44-52. https://doi.org/10.1037/0735-7036.117.1.44

38. Bennett V, Gourkow N, Mills DS. Facial correlates of emotional behaviour in the domestic cat (Felis catus). Behav Process. 2017;141:342-50. https://doi. org/10.1016/j.beproc.2017.03.011.

39. Ellis SLH. Recognising and assessing feline emotions during the consultation. History, body language and behaviour. J Feline Med Surg. 2018:20:445-56. https://doi.org/10.1177\%2F1098612X18771206.

40. Delgado $\mathrm{M}$, Hecht J. A review of the development and functions of cat play, with future research considerations. Appl Anim Behav Sci. 2019;214:117. https://doi.org/10.1016/j.applanim.2019.03.004.

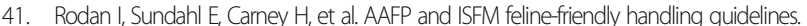
J Feline Med Surg. 2011;13(5):364-75. https:/doi.org/10.1016\%2F.j.jms.2011.03.012.

42. Hargrave C. Ouch! Understanding and reducing patients' frustration to improve patient welfare and reduce staff injuries. Compan Anim. 2017;22(9): 510-5. https://doi.org/10.12968/coan.2017.22.9.510.

43. Endersby S. Setting up a cat friendly clinic. Vet Nurse. 2018;9(6):284-93. https://doi.org/10.12968/vetn.2018.9.6.284.

44. Arrandale L, Buckley L. Towels versus hides: which are best at reducing acute stress in the newly hospitalised domestic cat (Felis sylvestris catus)? VNJ. 2017;32(10):285-8. https://doi.org/10.1080/17415349.2017.1343536.

45. Rodgers RJ, Cao B-J, Dalvi A, Holmes A. Animal models of anxiety: an ethological perspective. Braz J Med Biol Res. 1997:30(3):289-304. https://doi.org/10.1590/S01 00-879X1997000300002

\section{Publisher's Note}

Springer Nature remains neutral with regard to jurisdictional claims in published maps and institutional affiliations. 